\title{
ANÁLISE TÉRMICA DA CARNE DE COELHOS ${ }^{1}$
}

\author{
Verônica A. FURUKAWA², Paulo J.A. SOBRAL ${ }^{3, *}$, Ana Mônica Q. B. HABITANTE²,
}

\author{
Jacinta D.F. GOMES ${ }^{2}$
}

\section{RESUMO}

O objetivo deste trabalho foi avaliar o efeito da adição de condimentos na carne de coelho, sobre a estabilidade térmica de suas proteínas miofibrilares. Retalhos de 24 músculos Longissimus dorsis foram moídos e misturados, para a obtenção de um lote homogêneo. Foram adicionados, em alíquotas dessa carne: 1,$0 ; 2,0$ ou 3,0\% de sal; 2,$5 ; 5,0$ ou 7,5\% de sacarose e 1,5; 3,0 ou 4,5\% de ácido acético 3\% em solução aquosa, e uma mistura perfazendo 3\% de sal, $5 \%$ de sacarose e 3\% da mesma solução de ácido acético. Após homogeneização manual, as amostras foram mantidas em repouso sob refrigeração, por 30 minutos. Alíquotas da ordem de $10 \mathrm{mg}$ foram usadas para análise térmica e o restante, para análises de $\mathrm{pH}$, proteínas e umidade. As análises térmicas foram realizadas em um calorímetro diferencial de varredura DSC-TA2010, a $10^{\circ} \mathrm{C} / \mathrm{min}$, entre 0 e $100^{\circ} \mathrm{C}$. As curvas de DSC da carne pura apresentaram endotermas nas temperaturas de (Td) $58,4\left(0,7^{\circ} \mathrm{C}\right.$ (miosina) e $78,2\left(0,2^{\circ} \mathrm{C}\right.$ (actina), envolvendo entalpia $(\triangle \mathrm{Hd}) \mathrm{de} 17,5 \mathrm{~J} / \mathrm{g}$ de proteinas. $\mathrm{O}$ sal e o ácido acético desestabilizaram as proteínas, provocando redução da Td da miosina e actina, contrariamente à sacarose, que apresentou efeito estabilizante. A adição da mistura dos condimentos desestabilizou as proteínas miofibrilares. Apenas o ácido, adicionado acima de $1,5 \%$, provocou desnaturação das proteínas.

Palavras-chave: proteínas miofibrilares; desnaturação; análise calorimétrica diferencial; sal; sacarose; ácido acético.

\section{SUMMARY}

THERMAL ANALYSIS OF RABBIT MEAT. The objective of this work was to evaluate the effect of some additives over the myofibrillar protein thermal stability of rabbit meat. Steaks of 24 Longissimus dorsis muscle were ground and mixed to obtain a homogeneous portion. Samples of this meat were added with: $1.0,2.0$, or $3.0 \%$ of salt; $2.5,5.0$, or $7.5 \%$ of saccharose and $1.5,3.0$ or $4.5 \%$ of acid acetic solution 3\%, and a mixture with 3\% salt, $5 \%$ saccharose and $3 \%$ of the same acid acetic solution. After manual homogenization, the samples were stored refrigerated for 30 minutes. The meat was analyzed for thermal behavior, pH, protein and water content. The thermal analysis was done with a differential scanning calorimeter DSC-TA2010, using samples of about $10 \mathrm{mg}$, at $10^{\circ} \mathrm{C} / \mathrm{min}$, between 0 and $100^{\circ} \mathrm{C}$. The DSC curves showed endothermic peaks (Td) at $58.4 \pm 0.7^{\circ} \mathrm{C}$ (myosin) and $78.2 \pm 0.2^{\circ} \mathrm{C}$ (actin), having enthalpy ( $\triangle \mathrm{Hd}$ ) of $17.5 \mathrm{~J} / \mathrm{g}$ of protein. The proteins were destabilized by the salt and by the acetic acid, leading to a reduction of myosin and actin Td, contrarily to the saccharose which showed a stabilizing effect. The addition of the mixture of additives destabilized the myofibrillar proteins. Only the acid, added above $1.5 \%$ caused protein denaturation.

Keywords: myofibrillar proteins; denaturation; differential calorimetric analysis; salt; saccharose; acetic acid.

\section{1 - INTRODUÇÃO}

O aquecimento da carne durante seu cozimento produz alterações na sua aparência, no seu sabor e na sua textura, ocorrendo encolhimento, liberação de suco celular, descoloração, que são causados por mudanças nas proteínas do músculo, que são termosensíveis [9]. Particularmente, as características funcionais e texturais da carne cozida dependem do comportamento térmico das proteínas miofibrilares [14].

A estrutura nativa das proteínas é estabilizada por forças moleculares internas, que são reduzidas com o aumento da temperatura [16]. Acima de certa temperatura, ocorre uma transição do tipo ordem-desordem, quando as proteínas são desenroladas ("unfolded"), ocorrendo um fenômeno conhecido como desnaturação. Esse fenômeno é uma transição de fase de primeira ordem, e pode ser caracterizado pela temperatura (Td) e entalpia de desnaturação $(\triangle \mathrm{Hd})$. O conhecimento de

\footnotetext{
1. Recebido para publicação em 20/02/2003. Aceito para publicação em 27/02/2004 (001070).

2. Departamento de Zootecnia. FZEA-USP. CP 23. CEP: 13635-900 Pirassununga (SP).

3. Departamento de Engenharia de Alimentos. FZEA-USP. CP 23. CEP:13635-900 Pirassununga (SP). Fax: Oxx19-3565.4114. E-mail: pjsobral@usp.br

* A quem a correspondência deve ser enviada.
}

Td é importante para o estabelecimento da temperatura final de cozimento [3] e por estar relacionada com as propriedades texturais de certos produtos processados [9], enquanto que a $\triangle \mathrm{Hd}$ deve ser conhecida e considerada nos cálculos de transferência de calor no produto durante o cozimento [4].

Segundo KIJOWSKI \& MAST [10], a desnaturação de proteínas pode ser estudada com o emprego de vários métodos, como solubilidade, viscosidade, fluorescência, atividade ATP-ase da miosina e disponibilidade de grupos sulfidrílicos, entre outros. Recentemente, esses estudos têm sido realizados por espectrometria (Infravermelho com transformada de Fourier, Raman, discroismo circular) e com a calorimetria diferencial de varredura [17], que permite o emprego das proteínas purificadas ou em sua forma natural, isto é, no músculo.

Diversas pesquisas têm sido realizadas com o emprego da calorimetria diferencial de varredura. Alguns trabalhos foram realizados com músculos de peixes apenas lavados [16] e com proteínas miofibrilares extraídas de músculos de pescados, verificando-se o efeito do processamento, do pH e da adição de sal e sacarose sobre a desnaturação protéica [14, 15]. KIJOWSKI \& MAST [10] determinaram a temperatura e a entalpia de desnaturação de proteínas de diversas partes da carcaça de frangos (carne, pele e sangue) e das proteínas dos músculos (miosina, actina, proteínas sarcoplasmáticas e do teci- 
do conectivo) desses mesmos animais. VAN LAACK \& LANE [19] e AMAKO \& XIONG [2] estudaram a estabilidade térmica de proteínas miofibrilares de frango em função do $\mathrm{pH}$ e da adição de carragenas $(\kappa, \imath, \lambda)$ e sal, respectivamente. Esse mesmo tipo de estudo foi realizado com carne suína por DE FREITAS et al. [6], que avaliaram a estabilidade térmica das proteínas miofibrilares devidamente extraídas e na carne moída, ambas adicionadas com as carragenas e sal.

Outros trabalhos foram realizados com proteínas de mamíferos. BERTOLA, BEVILACQUA \& ZARITZKI [3] estudaram o efeito de diversos tratamentos térmicos (a úmido) sobre a textura da carne bovina, acompanhando-se a desnaturação das proteínas por DSC. E ENSOR, SOFOS \& SCHIMIDT [7] estudaram a estabilidade térmica das proteínas do músculo semimembranoso bovino em função da adição de alginato e cálcio.

Outra espécie bastante estudada é o coelho, porém praticamente todos os estudos consultados são de interesse biomédico. Consultando-se a literatura internacional, observou-se que apenas WRIGHT, LEACH \& WILDING [21] e WRIGHT \& WILDING [22] estudaram a desnaturação das proteínas miofibrilares de carne de coelhos com interesse tecnológico, verificando respectivamente, o efeito do $\mathrm{pH}$ e força iônica na carne, e da adição de três tipos de fosfatos (orto, piro e tripolifosfatos), normalmente usados para aumentar a capacidade de retenção de água da carne, sobre a desnaturação da miosina e seus subfragmentos.

Em uma revisão bibliográfica recente, FURUKAWA [8] observou que apesar do considerável crescimento da criação racional de coelhos, a produção nacional de carne dessa espécie é muito pequena (20 mil toneladas/ ano em 2001, segundo IBGE [11]) em relação à carne de bovinos, suínos e de frangos, e que, possivelmente por isso, a qualidade (intrínseca) da carne de coelhos é ainda pouco estudada no Brasil. Mas, o consumo da carne de coelhos, que foi de apenas $0,07 \mathrm{~kg} /$ habitante/ano em 1995 [5], deve ser incentivado, pois ela apresenta características nutricionais muito interessantes, apresentando baixo teor de lipídios (dos quais, 56\% de poliinsaturados), de colesterol e de sódio [13].

Tentando-se contribuir para se reverter o quadro acima descrito, o objetivo deste trabalho foi o estudo do efeito da adição de sal, sacarose e/ou ácido acético sobre a desnaturação das proteínas da carne de coelhos, empregando-se a calorimetria diferencial de varredura.

\section{2 - MATERIAIS E MÉTODOS}

Utilizaram-se neste trabalho, carnes de coelhos mestiços (Califórnia X Nova Zelândia branco) criados no Campus da USP de Pirassununga e abatidos no Matadouro-Escola do próprio Campus, com idade média de 72 dias e peso médio da ordem de $2 \mathrm{~kg}$. Retalhos do músculo Longissimus dorsis de 12 carcaças de coelhos, coletados 24 horas após o abate, foram moídos, em um processador doméstico com facas, e misturados para a obtenção de um único lote homogêneo de carne. Esse lote foi separado em diversas alíquotas, embaladas (sem vácuo) em sacos de polietileno, congeladas com nitrogênio líquido e transferidas posteriormente para congelador doméstico, evitando-se assim, possível desnaturação das proteínas causada pelo congelamento lento, se fossem colocados diretamente no congelador. Quando necessárias, as alíquotas eram descongeladas em geladeira, pelo período de uma noite.

As amostras foram preparadas pela adequada adição de 1,$0 ; 2,0$ ou 3,0\% de sal (comercial); 2,5; 5,0 ou $7,5 \%$ de sacarose (comercial) e 1,5; 3,0 ou $4,5 \%$ de uma solução a 3\% de ácido acético glacial (Synth) na carne moída, tendo sido preparadas ainda, amostras com 3\% de sal, $5 \%$ de sacarose e 3\% da mesma solução de ácido acético. As pesagens $( \pm 0,01 \mathrm{~g})$ das amostras de carne e dos aditivos foram realizadas em balança semi-analítica (Marte, AS2000), preparando-se sempre amostras da ordem de 20g. Após mistura manual, as amostras foram mantidas em repouso por 30 minutos, para possibilitar uma perfeita distribuição dos aditivos na carne, sempre em condição de refrigeração.

Para as análises por calorimetria diferencial de varredura, uma alíquota da ordem de $10 \mathrm{mg}$ era retirada de cada amostra recém-preparada, colocada em panelinhas TA de alumínio, fechadas hermeticamente e pesadas $( \pm 0,01 \mathrm{mg})$ em balança de precisão (Ohaus, Analytical Plus). Essas análises foram realizadas em um calorímetro diferencial de varredura DSC-TA2010, com controlador TA5000 (TA Instruments), operando com fluxo de $45 \mathrm{~mL} / \mathrm{min}$ de $\mathrm{N}_{2}$, taxa de aquecimento de $10^{\circ} \mathrm{C} / \mathrm{min}$, entre 0 e $100^{\circ} \mathrm{C}$ e com uma panelinha vazia como referência. $\mathrm{O}$ aparelho foi calibrado com Índio $\left(\mathrm{T}=156,6^{\circ} \mathrm{C}\right.$ e $\triangle \mathrm{H}=28,71 \mathrm{~J} / \mathrm{g}$ ). Considerou-se como temperatura (Td) e entalpia $(\triangle \mathrm{Hd})$ de desnaturação, a temperatura onde ocorreu o pico e a área sobre as endotermas, respectivamente, ambos calculados com o emprego do programa Universal Analysis V.2.5H (TA Instruments). As análises foram realizadas em triplicatas.

O restante das amostras era utilizado para análises de $\mathrm{pH}$, teor de proteínas e umidade, sempre em triplicatas. $\mathrm{O}$ pH foi determinado diretamente na amostra com um peagâmetro digital (Hanna Instruments, HI8314), e o teor de proteína bruta e a umidade determinados segundo métodos clássicos [1].

Os dados obtidos da análise com o DSC foram submetidos à análise de variância (ANOVA) empregandose o programa Statistica 5.0 (StatSoft, INC., Tulsa, OK).

\section{3 - RESULTADOS E DISCUSSÕES}

Os resultados das análises químicas das amostras preparadas para calorimetria diferencial de varredura, médias entre triplicatas, estão apresentados na Tabela 1 , onde se pode observar que a carne de coelho é uma excelente fonte de proteínas (21\%). A ligeira redução do teor de proteínas nas amostras é devido ao incremento dos vários aditivos estudados. Esse mesmo comportamento pode ser observado e explicado para a va- 
riação da umidade das amostras. Os teores de proteínas das amostras foram usados no cálculo da entalpia de desnaturação em termos de proteínas, isto é, como Joules/g de proteínas, evitando-se assim uma possível fonte de erro.

TABELA 1. Resultados das análises químicas das amostras preparadas para calorimetria diferencial de varredura ${ }^{1}$

\begin{tabular}{|c|c|c|c|c|}
\hline Aditivos & Concentração & $\begin{array}{c}\text { Proteínas } \\
\text { (g/100g amostra) }\end{array}$ & $\begin{array}{c}\text { Umidade } \\
\text { (g água/100g } \\
\text { amostra) }\end{array}$ & $\mathrm{pH}$ \\
\hline Controle $^{2}$ & & $21,2(0,9)$ & $76,4(0,1)$ & $5,7(0,0)$ \\
\hline \multirow[t]{3}{*}{$\mathrm{Sal}(\mathrm{NaCl})$} & $1 \%$ & $20,9(0,6)$ & $75,8(0,4)$ & $5,7(0,0)$ \\
\hline & $2 \%$ & $20,8(0,2)$ & $75,8(0,2)$ & $5,7(0,0)$ \\
\hline & $3 \%$ & $20,5(0,2)$ & $74,5(0,5)$ & $5,6(0,0)$ \\
\hline \multirow[t]{3}{*}{ Sacarose } & $2,5 \%$ & $21,2(0,5)$ & $74,1(0,1)$ & $5,8(0,0)$ \\
\hline & $5,0 \%$ & $20,1(0,4)$ & $73,0(0,1)$ & $5,8(0,0)$ \\
\hline & $7,5 \%$ & $18,5(0,6)$ & $71,4(0,2)$ & $5,8(0,0)$ \\
\hline \multirow[t]{3}{*}{ Àcido acético a 3\% } & $1,5 \%$ & $21,4(0,5)$ & $76,9(0,2)$ & $5,7(0,0)$ \\
\hline & $3,0 \%$ & $21,3(0,2)$ & $76,9(0,2)$ & $5,7(0,0)$ \\
\hline & $4,5 \%$ & $21,3(1,0)$ & $77,4(0,2)$ & $5,5(0,0)$ \\
\hline Mistura $^{3}$ & & $18,8(0,7)$ & $71,0(0,3)$ & $5,5(0,0)$ \\
\hline
\end{tabular}
de ácido acético $3 \%$.

Por outro lado, observou-se que o $\mathrm{pH}$ permaneceu praticamente constante, sempre em torno de 5,7, com exceção da amostra preparada com a concentração máxima da solução de ácido acético e com a mistura de aditivos. Essa insensibilidade do $\mathrm{pH}$ aos aditivos usados neste trabalho, é provavelmente, conseqüência do efeito tampão das proteínas da carne. Dessa forma, as possiveis alterações na estabilidade térmica das proteínas não podem ser explicadas em termos de variação do pH, e sim da presença do próprio aditivo.

Curvas típicas obtidas por calorimetria diferencial de varreduras, também chamadas de termogramas, estão apresentadas na Figura 1. Pode-se observar no termograma da carne sem aditivos (a), a ocorrência de duas nítidas endotermas e uma inflexão ("shoulder") após o primeiro pico. A primeira endoterma $\left(\mathrm{Td}=58,4 \pm 0,7^{\circ} \mathrm{C}\right)$ está associada à desnaturação da miosina e a segunda $\left(\mathrm{Td}=78,2 \pm 0,2^{\circ} \mathrm{C}\right)$, a da actina. Esses resultados são similares aos obtidos por WRIGHT, LEACH \& WILDING [21], que determinaram $\mathrm{Td}=60^{\circ} \mathrm{C}$ da miosina e $\mathrm{Td}=80^{\circ} \mathrm{C}$ da actina de coelho, e por KIJOSWSK \& MAST [10], trabalhando com carne de frango: $57^{\circ} \mathrm{C}$ para a miosina e $78^{\circ} \mathrm{C}$ para a actina. Observa-se ainda no trabalho de WRIGHT, LEACH \& WILDING [21] que a desnaturação das proteínas sarcoplasmáticas $\left(\mathrm{Td}=67^{\circ} \mathrm{C}\right)$ ocorreu na faixa intermediária entre a miosina e actina. Assim, pode-se explicar a inflexão ocorrendo em $\mathrm{T}=63,3 \pm 0,3^{\circ} \mathrm{C}$, após o primeiro pico, como conseqüência da desnaturação de alguma fração dessas proteínas. Resultados semelhantes podem ser observados em diversos trabalhos da literatura [12, 15, 16, 18, 21, 22].

Em virtude da ocorrência de duas, ou mais, transições seguidas, o cálculo das entalpias envolvidas na desnaturação de cada fração é difícil. Assim, calculou-se a entalpia de desnaturação de todas as frações protéicas, que foi de $17,5 \pm 0,7 \mathrm{~J} / \mathrm{g}$ de proteínas da carne sem aditivos. Esse resultado está de acordo com o obtido por WRIGHT, LEACH \& WILDING [21], que determinaram a entalpia de desnaturação das proteínas da carne de coelho como sendo $16,8 \mathrm{~J} / \mathrm{g}$ de proteínas.

Observa-se na Figura 1, que a adição de todos os aditivos utilizados modificaram os perfis das curvas de DSC, conseqüência da alteração da estabilidade térmica das proteínas. A diminuição dessa estabilidade implicou na redução da temperatura de desnaturação [15]. A presença do sal na carne diminuiu o tamanho do pico endotérmico (Figura $1 b, c, d$ ) relativo à miosina, fazendo aparecer um pouco mais nitidamente, o pico intermediário (proteínas sarcoplasmáticas e/ou do tecido conectivo), contrariamente à sacarose (Figura 1e,f,g), que por aumentar o pico da miosina, principalmente a $2,5 \mathrm{e}$ $5 \%$, escondeu esse pico. O ácido acético (Figura $1 h, i, j$ ), por sua vez, proporcionou um perfil praticamente idêntico ao da carne pura, porém também colocando em evidência o pico intermediário, devido a uma ligeira redução do pico da miosina.

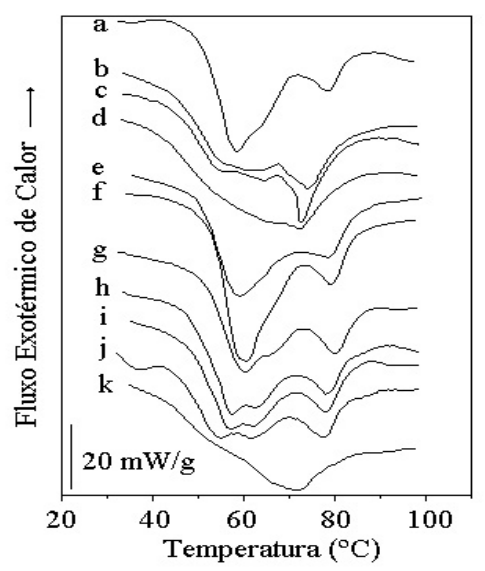

FIGURA 1. Exemplos de curvas de DSC das amostras de carne de coelho preparadas: a) sem aditivos; e com b) $1 \%$ de sal, c) $2 \%$ de sal, d) $3 \%$ de sal; e) $2,5 \%$ de sacarose, f) 5\% de sacarose, g) 7,5\% de sacarose; h) $1,5 \%$ de ác. acético $3 \%$, i) $3 \%$ de ác. acético $3 \%$, j) 4,5\% de ác. acético $3 \%$; k) 3\% de sal, $5 \%$ de sacarose e $3 \%$ de ac. acético $3 \%$.

A maior alteração do perfil dos termogramas foi causado pela adição da mistura dos aditivos. Observa-se na respectiva curva (Figura $1 k$ ), a ocorrência de praticamente uma endoterma, de maneira similar ao ocorrido com a adição de $3 \%$ de sal (Figura $1 d$ ), podendo-se sugerir que o efeito desestabilizador do sal não foi compensado pelo efeito estabilizador da sacarose.

Pode-se observar na Figura 2, que o sal desestabilizou, mesmo em baixas concentrações, a miosina e a actina, reduzindo significativamente $(\mathrm{P}<0,05)$ suas Td para $55,3 \pm 0,5$ e $71,5 \pm 1,3^{\circ} \mathrm{C}$, respectivamente, a $3 \%$. Apesar de diminuir a endoterma da miosina, o maior efeito desestabilizador do sal, expresso como redução de Td, foi sobre a actina, cuja redução em relação à carne sem aditivos foi superior a $6^{\circ} \mathrm{C}$. Esses com- 
portamentos estão de acordo com os obtidos por PAREDI et al. [14], que observaram redução da Td das proteínas miofibrilares de um tipo de ostra com o incremento da força iônica de uma solução adicionada, e por DE FREITAS et al. [6], que adicionaram $2 \%$ de sal em carne suína moída.

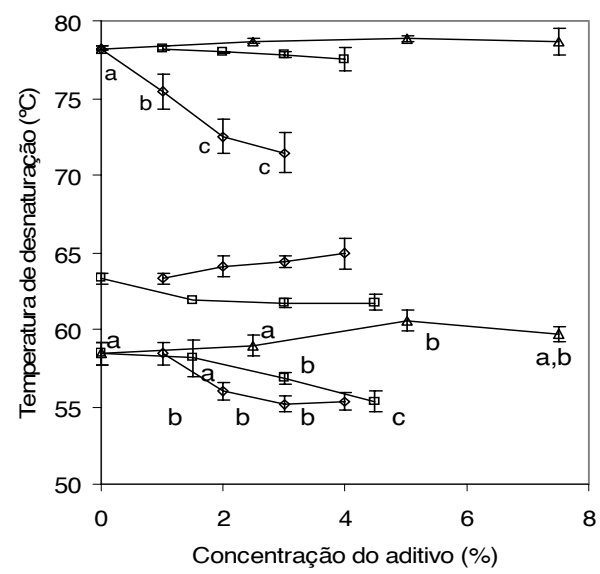

FIGURA 2. Temperatura de desnaturação das proteínas da carne de coelho em função do tipo e concentração dos aditivos: $\diamond$ sal, $\triangle$ sacarose, $\square$ ácido acético $3 \%$. Médias com letras diferentes no mesmo tratamento são significativamente diferentes $(\mathrm{P}<0,05)$.

O ácido acético também provocou efeito desestabilizador das proteínas, reduzindo $(\mathrm{P}<0,05)$ a $\mathrm{Td}$ da miosina até $55,3 \pm 0,7^{\circ} \mathrm{C}$, a $7,5 \%$ de ácido acético $3 \%$, mas praticamente não afetou $(\mathrm{P}>0,05)$ a actina $\left(\mathrm{Td} \sim 77^{\circ} \mathrm{C}\right)$. Esse comportamento não pode ser explicado pelo efeito do $\mathrm{pH}$, pois mesmo no caso das amostras com 4,5\% de ácido acético $3 \%$, o $\mathrm{pH}$ variou muito pouco $(5,5) \mathrm{em}$ relação à carne pura $(5,7)$. Infelizmente, não se encontraram trabalhos sobre o efeito do ácido acético na estabilidade das proteínas miofibrilares para comparações.

Contrariamente aos outros dois aditivos, a sacarose apresentou efeito estabilizante das proteínas, mais pronunciado na miosina, cuja Td atingiu valores da ordem de $60^{\circ} \mathrm{C}$, com $5 \%$ de sacarose, significativamente $(\mathrm{P}<0,05)$ superior à $\mathrm{Td}$ da carne pura, que na actina, cuja Td variou entre 78 e $79^{\circ} \mathrm{C}(\mathrm{P}>0,05)$. Esse efeito estabilizante da sacarose também foi observado por PARK \& LANIER [16] que adicionaram 8\% de sacarose em músculo lavado de Tilápia e observaram que a Td da miosina aumentou de cerca de 55 para $57,5^{\circ} \mathrm{C}$. Segundo WIMMER et al. [20], o aumento de Td provocado pela adição de polióis (ou açúcares) é explicado pelo efeito do ordenamento do solvente (água) em torno das moléculas de proteínas, provocando conseqüentemente, aumento das interações hidrofóbicas nessas macromoléculas.

No caso da adição da mistura dos aditivos, a Td da miosina diminuiu para $53,8 \pm 1,5^{\circ} \mathrm{C}$, mas a $\mathrm{Td}$ da actina sofreu menor diminuição, atingindo $75,7 \pm 2,6^{\circ} \mathrm{C}$, possivelmente devido ao efeito protetor da sacarose. Esse comportamento está de acordo com o observado por PARK \& LANIER [16], que adicionaram 3\% de sal e $8 \%$ de sacarose em músculo lavado de Tilápia, observando que o açúcar não restaurou totalmente a perda da estabilidade das proteínas causada pelo sal.

Apesar do sal ter desestabilizado as proteínas de maneira mais importante que o ácido acético, apenas a adição de 3 e 4,5\% do ácido provocou desnaturação das proteínas $(\mathrm{P}<0,05)$ (Figura 3).

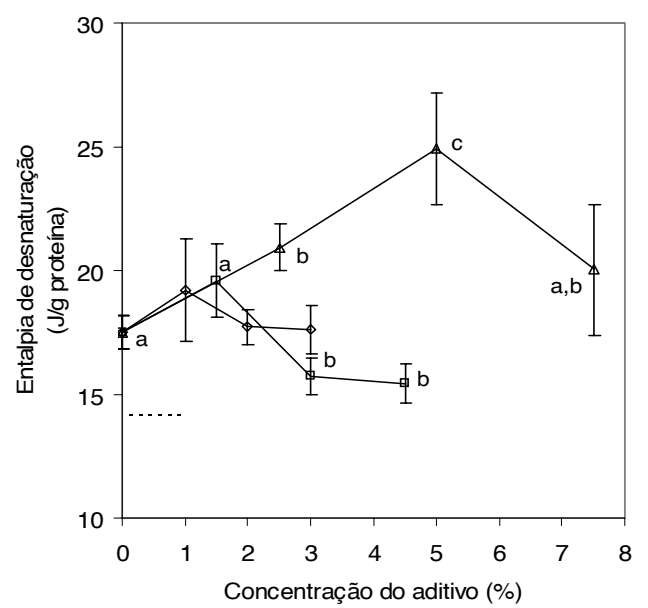

FIGURA 3. Entalpia de desnaturação das proteínas da carne de coelho em função do tipo e concentração dos aditivos: $\diamond$ sal, $\triangle$ sacarose, $\square$ ácido acético $3 \%$. O traço pontilhado indica o resultado da adição de $3 \%$ de sal, $5 \%$ de sacarose e 3\% de ácido acético 3\%. Médias com letras diferentes no mesmo tratamento são significativamente diferentes $(\mathrm{P}<0,05)$.

Na concentração de $3 \%$ de sal, a $\triangle \mathrm{Hd}$ foi de $17,6 \mathrm{~J} / \mathrm{g}$ de proteínas, equivalente à da carne pura $(\mathrm{P}>0,05)$. Mas, com $3 \%$ de ácido acético $3 \%, \triangle \mathrm{Hd}$ foi de $15,7 \mathrm{~J} / \mathrm{g}$ de proteínas, indicando menos proteínas na forma nativa na amostra analisada. Por outro lado, a sacarose aumentou $(\mathrm{P}<0,05)$ a $\triangle \mathrm{Hd}$ que atingiu $20 \mathrm{~J} / \mathrm{g}$ de proteínas a $7,5 \%$ de sacarose, provocado pelo efeito estabilizante desse produto, valor esse comparável à entalpia de desnaturação $(\triangle \mathrm{Hd}=22,5 \mathrm{~J} / \mathrm{g}$ de proteínas) de miofibrilas purificadas de músculo de coelho, determinada por WRIGHT, LEACH \& WILDING [21]. PAREDI et al. [14] estudaram a estabilidade térmica das proteínas miofibrilares de um tipo de ostra em função da força iônica de uma solução adicionada e observaram uma contínua redução da respectiva entalpia de desnaturação, contrariamente ao observado neste trabalho. Segundo SMITH [17], os estudos sobre desnaturação de proteínas devem ser conduzidos em sistemas diluídos, para se evitar interações intermoleculares, como a agregação, que são fenômenos exotérmicos. Logo, pode-se sugerir que os valores crescentes de $\triangle \mathrm{Hd}$ observados na Figura 3 , foram conseqüência da segunda etapa da desnaturação, qual seja, a agregação das proteínas. Entretanto, mais estudos são necessários para explicar estes resultados.

\section{4 - CONCLUSÕES}

A adição de sal na carne de coelho diminuiu a estabilidade térmica de suas proteínas miofibrilares, pro- 
vocando redução das temperaturas de desnaturação da miosina e da actina. O ácido acético, conforme usado neste trabalho, também provocou a desestabilização das proteínas, porém de maneira mais acentuada na miosina que na actina. Por outro lado, o emprego da sacarose estabilizou as proteínas miofibrilares, aumentando consideravelmente a temperatura de desnaturação da miosina. Entretanto, apesar do efeito protetor desse açúcar, a adição da mistura de condimentos desestabilizou as proteínas, principalmente a miosina.

Apesar do efeito desestabilizante do sal, apenas a adição de 2,5 e 5,0\% da solução de ácido acético 3\% provocou desnaturação a frio das proteínas, observado pela diminuição da entalpia envolvida na desnaturação.

\section{5 - REFERÊNCIAS BIBLIOGRÁFICAS}

[1] A.O.A.C. Official Methods of Analysis. V.2, 16 Ed. Association of Official Analysis Chemists, Washington, DC, 1997

[2] AMAKO, D.E.N.; XIONG, Y.L. Effects of carrageenan on thermal stability of proteins from chicken thigh and breast muscles. Food Research International, v. 34, p. 247-253, 2001.

[3] BERTOLA, N.C.; BEVILACQUA, A.E.; ZARITZKI, N.E. Heat treatment effect on texture changes and thermal denaturation of proteins in beef muscle. Journal of Food Processing and Preservation, v. 18, p. 31-46, 1994.

[4] CARCIOFI, B.A.M.; FAISTEL, J.; ARAGÃO, G.M.F.; LAURINDO, J.B. Determination of thermal diffusivity of mortadella using actual cooking process data. Journal of Food Engineering, v. 55, p. 89-94, 2002.

[5] COLIN, M. La cuniculture Sud-Américaine: Le Brésil. World Rabbit Science, v. 3, n. 2, p. 85-90, 1995.

[6] DEFreitAs, Z.; SEBRANEK, J.G.; OLSON, D.G.; CARR, J.M. Carrageenan effects thermal stability of meat proteins. Journal of Food Science, v. 62 , n. 3, p. 544-547, 1997.

[7] ENSOR, S.A.; SOFOS, J.N.; SCHMIDT, G.R. Differential scanning calorimetric studies of meat protein-alginate mixtures. Journal of Food Science, v. 56, n. 1, p. 175-181, 1991.

[8] FURUKAWA, V.A. Efeito da suplementação de vitamina $\mathbf{E}$ na dieta sobre a qualidade da carne congelada de coelhos. Pirassununga, 2002, 64 p. Dissertação (Mestre em Qualidade e Produtividade Animal). Faculdade de Zootecnia e Engenharia de Alimentos, Universidade de São Paulo (USP).

[9] GARCIA, F.T.; GAGLEAZZI, U.A.; SOBRAL, P.J.A. Variação das propriedades físicas e químicas do salame tipo italiano durante secagem e fermentação. Brazilian Journal of Food Technology, v. 3, p. 151-158, 2000.

[10] KIJOWSKI, J.M.; MAST, M.G. Thermal properties of proteins in chicken broiler tissues. Journal of Food Science, v. 53, n. 2, p. 363-366, 1988.
[11] IBGE, 2003. http://www.ibge.gov.br/mtexto/ppm.htm. Acesso em: janeiro de 2003.

[12] MONTERREY-QUINTERO, E.S.; SOBRAL, P.J.A. Preparo e caracterização de proteínas miofibrilares de tilápia do nilo (Oreochromis niloticus) para elaboração de biofilmes. Pesquisa Agropecuária Brasileira, v. 35, n. 1, p. 179-190, 2000.

[13] OUHAYOUN, J. La viande du lapin. Caractéristiques e variabilité qualitative. Cuni-Science, v. 7, p. 1-15, 1992.

[14] PAREDI, M.E.; TOMAS, M.C.; CRUPKIN, M.; AÑON, M.C. Thermal denaturation of Aulacomya ater ater (Molina) myofibrillar proteins: a differential scanning calorimetric study. Journal of Agricultural and Food Chemistry, v. 42, n. 4, p. 873-877, 1994.

[15] PARK, J.W.; LANIER, T.C. Scanning calorimetric behavior of tilapia myosin and actin due to processing of muscle and protein purification. Journal of Food Science, v. 54, n. 1, p. 49-51, 1989.

[16] PARK, J.W.; LANIER, T.C. Effects of salt and sucrose addition on thermal denaturation and aggregation of water-leached fish muscle. Journal of Food Biochemistry, v. 14, p. 395-404, 1990.

[17] SMITH, D.M. Protein interactions in gels: protein-protein interactions. In: Hettiarachchy, N.S., Ziegler, G.R., (Eds). Protein Functionality in Food Systems. New York, USA. Marcel Dekker, Inc., 1994. p. 209-224.

[18] SOBRAL, P.J.A.; OCUNO, D.; SAVASTANO JR., H. Preparo de proteínas miofibrilares de carne e elaboração de biofilmes com dois tipos de ácidos: propriedades mecânicas. Brazilian Journal of Food Technology, v. 1, p. 44-52, 1998.

[19] VAN LAACK, R.L.J.M.; LANE, J.L. Denaturation of myofibrillar proteins from chicken as affected by $\mathrm{pH}$, temperature, and adenosine triphosphate concentration. Poultry Science, v. 79, n. 1, p. 105-109, 2000.

[20] WIMMER, R.; OLSSON, M.; PETERSEN, M.T.N.; HATTIKAUL, R.; PETERSEN, S.B.; MÜLLER, N. Towards a molecular level understanding of protein stabilization: the interaction between lysozyme and sorbitol. Journal of Biotechnology, v.55, p. 85-100, 1997.

[21] WRIGHT, D.; LEACH, I.B.; WILDING, P. Differential scanning calorimetric studies of muscle and its constituent proteins. Journal of Science of Food and Agriculture, v. 28, p. 557-564, 1977.

[22] WRIGHT, D.; WILDING, P. Differential scanning calorimetric study of muscle and its proteins: myosin and its subfragments. Journal of Science of Food Agricultural, v. 35, p. 357-372, 1984.

\section{6 - AGRADECIMENTOS}

À Prefeitura do Campus Administrativo de Pirassununga (PCAPS-USP), pela colaboração com o fornecimento das carnes. Ao CNPq, pela bolsa PQI de PJAS. 